\title{
The Spillover Effect of Ecological Environment Protection on Poverty Reduction
}

\author{
Danmeng Feng ${ }^{1}$, Xiang Fan ${ }^{1}$, Xiaoyuan $\mathrm{Chu}^{2}$ \\ ${ }^{1}$ School of Economics and Resource Management, Beijing Normal University, Beijing, China \\ ${ }^{2}$ School of Public Management, Beijing University of Posts and Telecommunications, Beijing, China \\ Correspondence: Danmeng Feng, School of Economics and Resource Management, Beijing Normal University, No.19, \\ Xinjiekouwai Street, Haidian District, Beijing, P.R. China.
}

Received: November 7, 2016

Accepted: April 25, $2017 \quad$ Available online: June 8, 2017

doi:10.11114/aef.v4i4.2472

URL: https://doi.org/10.11114/aef.v4i4.2472

\begin{abstract}
This paper focuses on the spillover effect of the ecological poverty reduction between 30 provinces in China, applying Durbin Model and spatial correlation analysis to find out the interaction between different areas about the ecological indicators on poverty reduction. The result shows that there a high correlation relationship of poverty rate on 30 provinces in China, especially the indicators of Factory Station, Use of Chemical Fertilizers and the proportion of all Rural Population of one region has significant effects on poverty alleviation in surrounding areas, which indicates that for ecological environment view, poverty alleviation in one regions is not only influenced by its own ecological indicators, but also by which in its nearby areas, indicating the ecological poverty alleviation has a spillover effect in China.
\end{abstract}

Keywords: spillover effect, ecological poverty reduction, correlation relationship

\section{Intruction}

Ecological poverty is a key content of the global poverty, it is also an important factor which can lead to the multidimensional poverty, such as health and sanitation. But comparing with the practice of ecological poverty, the research of ecological poverty theory is far behind. DavidPierce. Wofford, MichaelPTodaro and SanJose consider that poor areas tend to have the characteristics of fragile ecological environment and ecological degradation. Based on this point of view, it can be pointed out that the fundamental reason of ecological poverty is the degradation of natural resource, which damages the functions of the ecological system and ecological environment. MichaelPTodaro (1992) also proposed that poverty leads to the deterioration of the ecological environment, the deterioration of the ecological environment and deepen the region's poverty.

In China, the research of ecological poverty is still in the exploration stage, which mainly focuses on two aspects. One is from the bearing capacity of population, resources and ecology, reflecting that ecological supply is not enough to support the ecological demand and ecological deficit, which exacerbats the deterioration of the ecological environment and then poverty problems will occur naturally. He Yunhong (2001) considers that the ecological poverty is refers to the deterioration of the regional ecological environment can not meet people in the basic necessities of life, which lead poor people into a vicious circle.Liu Yanmei (2005) believes that in some extent, the poverty of ecologically fragile areas is an ecological problem, which is closely related to the occurrence of poverty and ecological environment. Guo Zhiyi, Fan Huaiyu, Li Juheng, (2002) think that ecological poverty is one of the main types of poverty, which is mainly from the perspective of economic geography and population, so that poverty is defined as the lack of living space. Yu Cunhai (2004), that the low quality of ecological environment, or negative impact on the ecological environment made by its evolution or human's social activities results in a basic survive recession and the lack of objective necessary material, leading to the poverty state which cannot meet people's basic needs. The shortcomings of this kind of view is only pay attention to the ecological problems in impact on the poor, but the two should be for the relationship of mutual integration, so this definition of poverty alleviation and development guidance is not strong, theoretical research often exist "ecological problems about ecological protection" defects. Second, the view of economic development means that in the process of economic development, only focus on economic development, ignoring the ecological environment management and ecological environment protection, resulting in ecological destruction and regional poverty. Liu Gang, 
Shen Lei, Liu Xiaojie, (2007) according to the special ecological environment of Yulin region, through hierarchical analysis found although the extensive mode of economic development, rapid growth for the economy, but resource rich area ecological environment affected, increasing pollution of the environment, leading to ecological poverty. In summary, ecological poverty is not only an economic poverty, but also a double poverty with the ecological poverty.

Looking to the world, the research of anti-poverty is not a new topic, but most focuses on the economic, institutional and demographic. In recent years, the ecological poverty reduction has been concerned gradually, in 1992, the United Nationsheld "environment and development" meeting in Rio De Janeiro, Brazil, and adopted the "twenty-first Century agenda", which includes the natural ecological environment protection issues. In 1994, the Chinese government published "China's 21st century population and environment and development white paper", putting forward the sustainable development strategy should establish the comprehensive decision-making mechanism of economic environment and economics, then the ecological anti-poverty were formally put on the agenda.

In China, the deterioration of ecological environment and poverty has become the consensus of the academic community. Zhang Lijian, Lv Kaiyu, Zhu Lizhi (2008) found that the occurrence of poverty and the location of the resource conditions were strongly positive correlation through the study of the occurrence of poverty in China. Emily, Liu hui (2013) found that there is the interaction between environment vulnerability and poverty in western areas according to the study of western region of China. Guo Huaicheng (2004) considers that there is a serious problem of poverty and ecological environmental in the western region of China, and the ecological environment is also a constraints for getting rid of poverty, since poverty and environmental problems are often intertwined together, the construction of a good ecological environment is the basis for the development of poor areas. Sun Xinmeng (2011) believes that the destruction of the production of resources in Sanjiang area hindered the region's farmers to get rid of poverty in the study of the source of poverty alleviation in the Sanjiang area.

As a conclusion, the ecological poverty reduction is the sustainable poverty alleviation mode which makes a balance of ecological environment protection and poverty reduction. It requires the government to improve the mechanism and make rational use of natural resources in poor areas on the perspective of ecological economy, aiming to make sustainable and healthy development in the poor regions.

In the studying of ecological poverty reduction effect, scholars have begun to consider the spatial correlation of poverty reduction effect. Related research shows that the ecological poverty reduction effect have the characteristics of spatial spillover, which can be concluded as two points of view: one is ecological spillover effect, which believes ecological poverty reduction can improve the ecological environment in surrounding areas, and protect the natural resources elements of poor areas, so that it can bring the positive externality because of environment improvement. The other view considers that ecological poverty reduction is beneficial to economic growth in poor areas, which increase the per capita net income of farmers to complete the poverty reduction task.

The view of ecological spillover considers that ecological regulation and environmental protection to can avoid the extensive development of poor areas. On the one hand to ensure the sustainability of local development, on the other hand it can produce positive externality on the surrounding area and get rid of the cycle of "ecologicalvulnerability-poverty-predatory-exploitation-ecological-deteriorate further-more poverty", so as to get rid of poverty gradually. Yan Li Lu, Shi Bao Ding, Wang rongcheng and Wang Yu (2010) found ecological reducing poverty is conducive to protect the ecological resources in surrounding areas and bring positive spillover effect according to the research on the ecologically fragile areas. But the disadvantage of this view is that there is no elaboration on how to improve the poverty alleviation. The view of income spillover considers that the ecological poverty reduction still focuses on poverty reduction, and therefore the ultimate goal is to achieve economic growth and to improve the income of farmers. According to the theory of marginal propensity to consume, the growth of per capita net income of farmers will have a partial contribution to consumption, part of the increase amount of consumption will on purchasing goods and services around, so as to improve the economic level of the surrounding areas. Pan wenqin(2012) have studied of spatial spillover effects of China's regional economic growth, it shows that the economic development of every area in China does not only rely on the regional capital, labor and human capital investment growth, and in a great extent it is also influenced by the demand scale which is created by the regional economic development. On one hand, there is a positive spatial autocorrelation of GDP per capita in China's provinces and regions; on the other hand, with the passage of time, the numbers of regions which are significantly related to neighboring provinces are also on the increase.

There is not much research on the spillover effect of ecological poverty reduction in China, especially for the empirical testing, since there is a limitation on the range of research areas and the statistical data is also difficult to get. Therefore this paper focuses on the spillover effect of ecological poverty reduction in China's rural areas, aiming to find out the interaction between the ecological factors and the poverty reduction effect in different areas. 


\section{Models and Methods}

\subsection{Spatial Correlation Test}

Spatial correlation is the correlation between the property value for distribution factor of adjacent areas, if the attribute value has the clustering tendency, then it can be shown that it has a positive correlation; otherwise, it is a negative correlation in the space. In this paper, we use the Moran index to test the spatial correlation of the research objects, which can be expressed as:

$$
\mathrm{I}=\sum_{\mathrm{i}=1}^{\mathrm{n}} \sum_{\mathrm{j}-1}^{\mathrm{n}} \mathrm{W}_{\mathrm{ij}}\left(\mathrm{Y}_{\mathrm{i}}-\mathrm{Y}\right)\left(\mathrm{Y}_{\mathrm{j}}-\mathrm{Y}\right) / \mathrm{S}^{2} \sum_{\mathrm{i}=1}^{\mathrm{n}} \sum_{\mathrm{j}=1}^{\mathrm{n}} \mathrm{W}_{\mathrm{ij}}
$$

Where $S^{2}=\frac{1}{n} \sum_{i=1}^{n}\left(Y_{i}-Y\right), Y=\frac{1}{n} \sum_{i=1}^{n} Y_{i}, Y_{i}$ represents the observation of the $i$-th area, $n$ is the total number of regions, represents the spatial weight matrix The test range is $(-1,1)$, the greater value shows the higher spatial correlation degree. When the statistical value is greater than zero, which means the positive spatial autocorrelation between areas; while the statistical value less than 0 means the negative correlation between areas; when the statistical value equal to 0 means there is no spatial correlation.

\subsection{Spatial Durbin Model}

The significant characteristic of Durbin model is that it considers not only the spatial correlation of independent variables, but also the spatial correlation of the independent variables, that is the dependent variables in one region is not only affected by its own independent variables, but also by the independent variables in neighboring regions. Since this paper mainly studies the spillover effect of ecological environmental protection on poverty reduction, including not only the influence of ecological environment on poverty reduction for the local region, but also for the nearby regions as well, therefore this paper selects Durbin model which can be expressed as:

$$
\mathrm{Y}=\alpha \theta_{\mathrm{n}}+\beta \mathrm{Wy}+\mathrm{gX}+\mathrm{WX} \gamma+\varepsilon
$$

Where $\mathrm{Y}$ represents the dependent variable, $\alpha$ is the constant, $\theta_{\mathrm{n}}$ is the unit matrix with $\mathrm{n}^{*} 1, \mathrm{~W}$ is the spatial weight matrix, $\beta$ represents the spatial coefficient, $X$ represents the independent variables, Wy and WX represent spatial lag of $\mathrm{y}$ and $\mathrm{X}$ respectively, $\mathrm{g}$ and $\gamma$ are regression coefficients.

\section{Data and Variables}

\subsection{Instruction of Variables}

The variables in this paper are from two dimensions: the ecological environment improvement (independent variable) and poverty reduction (dependent variable). The ecological environment improvement are mainly based on the "China Statistical Yearbook", "China Statistical Yearbook" and "Chinese rural poverty monitoring report", selecting 4 second-level indicators and 14 third-level indicators in four aspects of the rural waterworks, renewable energy utilization, agricultural irrigation and agricultural chemical fertilizers, the area of agricultural plastic film and pesticide use. The dimension of "Access to Drinking Water Improvement" includes five indicators which are "Rural Population", "Population of Benefiting from Drinking Water Improvement", "Factory Station (unit)", "Accumulative Benefiting Population", " $\%$ of all Rural Population"; the dimension of "renewable energy" includes "Total Production of Methane (10000 cu.m)","Methane Generating Projects of Disposing Agricultural Wastes", "Water Heaters Using Solar Energy (10000 sq.m)"; The dimension of "Agricultural irrigation and fertilizer application" includes the indicators of "Area Irrigated (1 000 hectares)" and "Use of Chemical Fertilizers (10 000 tons)"; The dimension of "Agricultural plastic film and pesticide usage" includes the indicators of "Use of Agricultural Plastic Film (ton)", "Use of Plastic Film for Covering Plants (ton)", "Area Covered by Plastic Film (hectare)", "Use of Pesticide (ton)". The dependent variable is the indicator of poverty incidence (see table 1). 
Table 1. Instruction of indicators

\begin{tabular}{llll}
\hline Indicators & $\begin{array}{l}\text { Maximum } \\
\text { value }\end{array}$ & $\begin{array}{l}\text { Minimum } \\
\text { value }\end{array}$ & Mean value \\
\hline Poverty Incidence & 45.10 & 0.00 & 11.77 \\
Rural Population & 8295.85 & 200.52 & 3170.93 \\
Benefiting from Drinking Water Improvement & 7738.39 & 268.30 & 3018.23 \\
Factory Station (unit) & 219918.00 & 29.00 & 20587.25 \\
Accumulative Benefiting Population & 6572.15 & 267.07 & 2366.83 \\
\% of all Rural Population & 99.99 & 40.22 & 77.26 \\
Total Production of Methane (10000 cu.m) & 236643.00 & 441.40 & 50657.84 \\
Methane Generating Projects of Disposing & 33179.00 & 17.60 & 5582.50 \\
Agricultural Wastes & 1164.20 & 2.60 & 220.66 \\
Water Heaters Using Solar Energy (10000 sq.m) & 5342.10 & 143.10 & 2079.08 \\
Area Irrigated (1 000 hectares) & 705.80 & 8.30 & 193.25 \\
Use of Chemical Fertilizers (10 000 tons) & 322965.00 & 3113.00 & 79456.45 \\
Use of Agricultural Plastic Film (ton) & 229798.00 & 2425.00 & 43584.94 \\
Use of Plastic Film for Covering Plants (ton) & 3600000.00 & 4053.00 & 591546.51 \\
$\begin{array}{l}\text { Area Covered by Plastic Film (hectare) } \\
\text { Use of Pesticide (ton) }\end{array}$ & 164924.00 & 1805.00 & 59700.93 \\
\hline
\end{tabular}

\subsection{Source of Data}

The data in this paper are from china's 30 provinces for five years (2010-2014) according to "China's Rural Poverty Monitoring Report" and "China's poverty alleviation and Development Yearbook" from 2010-2014, which mainly focuses on the analysis of the intrinsic linkage between poverty reduction and the country's rural environmental governance level.

\section{Measurement Test, Model Setting and Result Analysis}

\subsection{Spatial Autocorrelation Test}

This paper uses GEODA soft ware to carry out the spatial autocorrelation effect of poverty incidence in 30 provinces in China (Tibet is not included since the lack of data). First, this paper constitutes a weight matrix based on the adjacent relationship of 30 provinces, which is expressed as a $30 * 30$ matrix with " $0-1$ ". In order to analyze the spatial features of poverty agglomeration among the regions, this paper calculates the positive spatial correlation of poverty incidence from 2010-2014 for 30 provinces by global Moran index, which can be seen as Figure 1. 


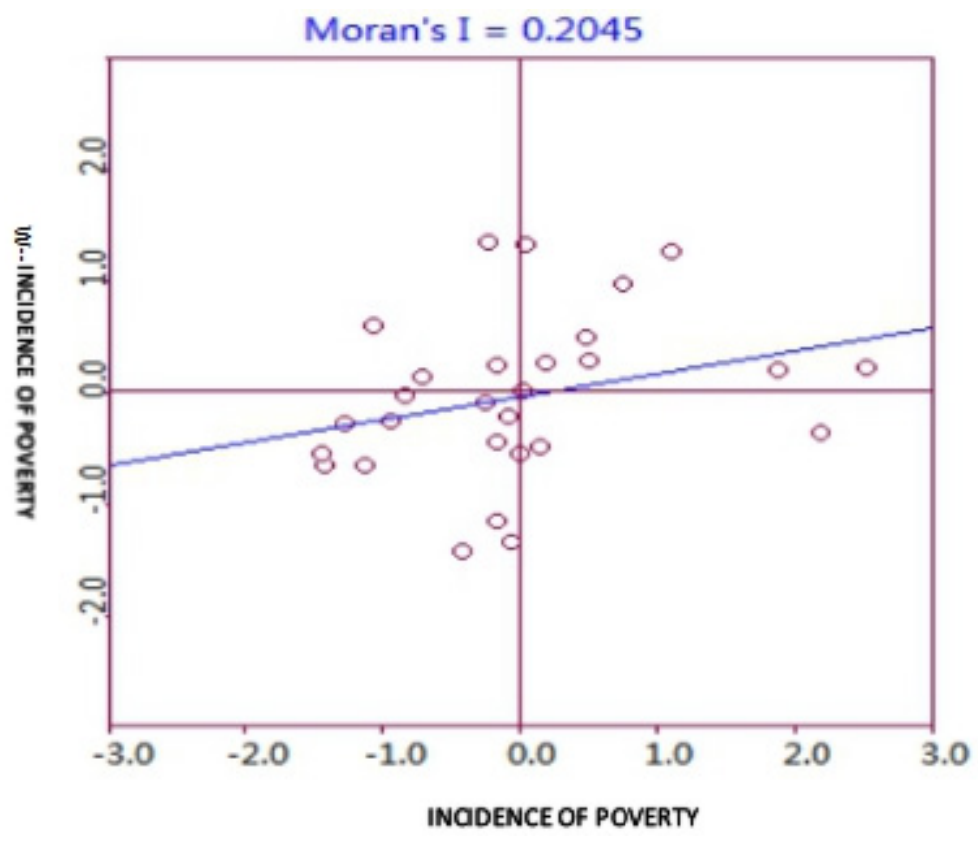

Figure 1. Moran index chart of Incidence of poverty

From figure one we can see the spatial autocorrelation value of poverty incidence in 30 provinces of China is 0.2045 and significant at $5 \%$ level, showing that these provinces has a high correlation on poverty incidence, which indicating that the poverty situation in on region can be influenced by other surrounding regions, on the contrary, this region's poverty situation also will affect its nearby regions' poverty. This result shows that the poverty incidence has a high regional correlation in China.

\subsection{Local Spatial Autocorrelation Test}

The result of global spatial autocorrelation shows that there is the phenomenon of spatial agglomeration for China's poverty incidence, but due to the different state of poverty in China's regions, in order to make a further analysis of the spatial agglomeration characteristics in China's poverty incidence, this paper takes Lisa concentration diagram to analyze the poverty incidence in China's poor rural regions (see as figure 2).

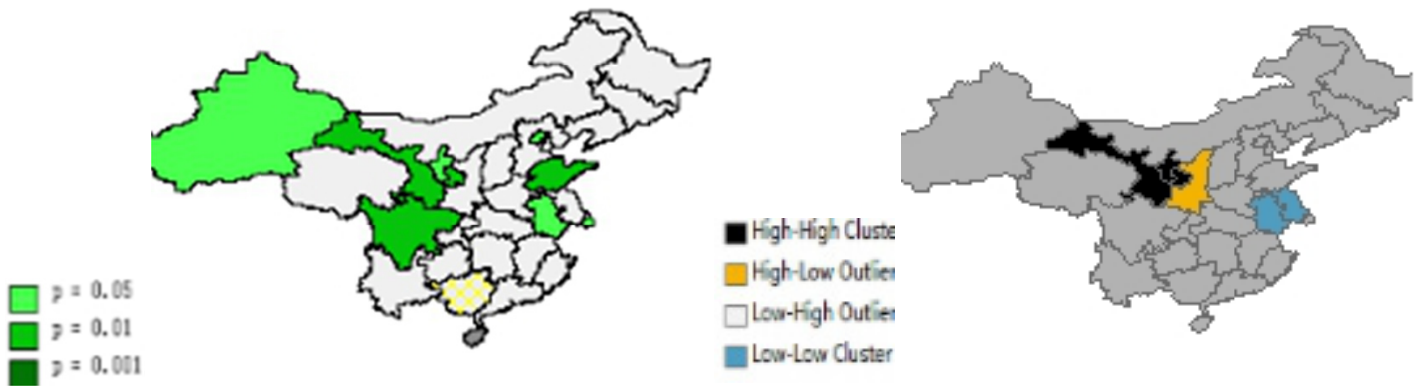

Figure 2. Lisa figure and agglomeration map of poverty incidence in China's 30 provinces

Notes: the map is not a complete map of the people's republic of China.

From the saliency map in the figure 2, it can be reflected that Gansu Province, Qinghai Province, Ningxia province and Shandong Province are distributed in the dark regions of the map, which indicates that the poverty incidence in these provinces are significant; from the Lisa cluster in figure2,it can be seen that Gansu province and Ningxia Province are distributed in the black area (H-H cluster), which means these provinces with high poverty incidence are surrounded by provinces with high poverty incidence, it can be seen as a high concentration areas with high poverty incidence. The yellow area (H-L cluster) mainly includes Shaanxi Province which indicates the provinces with high poverty incidence are surrounded by provinces with low poverty incidence, it can be seen that in yellow areas, the provinces will be positively influenced by the nearby provinces which are less poor. The blue area (L-L cluster) includes Anhui province and Jiangsu province, which means the provinces with low poverty incidence are surrounded by provinces with low 
poverty incidence. While the L-H cluster means the provinces with low poverty incidence are surrounded by provinces with high poverty incidence, there is no such provinces are included in this area, which suggests that if one province are surrounded by provinces with high poverty incidence, then this province will be restrict on poverty alleviation, it is very difficult to develop. It also reflects that there is a strong correlation on poverty between regions, so that it has an agglomeration effect on poverty between areas.

\subsection{Calculation results of Durbin Model}

According to the calculation of Durbin Model and Hausman test by using stata12.0 software to analyze the spillover effect of ecological poverty reduction in the rural regions of China's 30 provinces. The result is as follows:

Table 2. Result of Durbin Model in China's 30 provinces

\begin{tabular}{lll}
\hline & Fixed Effect & \\
\hline & coefficient & Z-statistic \\
Factory Station(unit) & -.00001 & 0.026 \\
Use of Chemical Fertilizers (10 000 tons) & -.1131 & 0.029 \\
\% of all Rural Population & -.4146 & 0.018 \\
Accumulative Benefiting Population & .0034 & 0.266 \\
Total Production of Methane (10000 cu.m) & -.00001 & 0.781 \\
Methane Generating Projects of & .00002 & 0.873 \\
Disposing Agricultural Wastes & & \\
Water Heaters Using Solar Energy (10000 sq.m) & -.0063 & 0.363 \\
Area Irrigated (1 000 hectares) & .0001 & 0.922 \\
Use of Agricultural Plastic Film (ton) & -.00002 & 0.769 \\
Use of Plastic Film for Covering Plants (ton) & -.0001 & 0.409 \\
Area Covered by Plastic Film (hectare) & -.00000 & 0.180 \\
Use of Pesticide (ton) & -.00000 & 0.940 \\
Hausman & $90.11(0.000)$ & \\
\hline
\end{tabular}

The hauseman test for the result is $90.11(0.000)$, since the spatial panel literatures mostly adopt fixed effect to analyze, therefore this paper selects the fixed effect as the final result of the analysis.

the regional ecological indicators have a certain effect on the poor effect of the surrounding areas, the indicator Factory Station(unit) of all Rural Population, Use of Chemical Fertilizers (10 000 tons) have significant influence on the poverty in $10 \%$ level, which indicate that these indicators in one region have a significant influence of poverty rate in other regions. For Factory Station, it has a low negative influence on the poverty rate in nearby regions $(-0.00001)$, which reflects the higher factory station number will decrease the poverty rate in nearby regions. For the use of chemical fertilizers, it has a higher negative influence on the poverty rate in nearby regions(-0.1131), this indicates that the high use of chemical fertilizers will not only affect the poverty in the local region, it will also has a positive spillover effect on the poverty alleviation in nearby regions. For the proportion of rural population, it also has a high negative influence on the poverty rate on nearby regions(-0.4146), which means the rural population is also a significant factor which has an positive effect on the poverty alleviation in nearby regions.

In other indicators which are not significant, the Accumulative Benefiting Population and Water Heaters Using Solar Energy has relatively higher effects, but the indicator Accumulative Benefiting Population has a positive influence on the poverty rate in nearby regions(0.0034), while the indicator of Water Heaters Using Solar Energy has a negative effect.

\section{Conclusion}

This paper focuses on the spillover effect on the environment dimension on the poverty in nearby regions based on the data in 30 provinces in China. The result can be concluded as three points: (1) According to the Moran I result, there a high correlation relationship of the poverty rate on 30 provinces in China. (2)Based on the adjacency weight, the environment dimension has a spillover effect on the poverty in nearby regions. (3) For the indicators of environment dimension, three indicators are significant and they all have negative influence on the poverty rate in nearby regions, which are Factory Station, Use of Chemical Fertilizers and the proportion of all Rural Population. (4) In other indicators which are not significant, the Accumulative Benefiting Population, Water Heaters Using Solar Energy and 
Accumulative Benefiting Population have the relatively higher influence than others.

From the result we confirm that standing on the regional level, the poverty in different regions in China has a high correlation, especially focusing on ecological environment dimension, we found the ecological indicators of poverty also have a spillover effect at different levels, We can conclude that one region's environment quality not only influences the local poverty alleviation effect, but also effects the surrounding areas' poverty alleviation. From the ecological dimension, the poverty alleviation breaks geographical boundaries and becomes a global issue.

\section{References}

Aunan, K., Fang, J. H., Vennemo, H., Oye, K., \& Seip, H. M. (2004). Co-Benefits of Climate Policy-Lessons Learned from a Study in Shanxi, China. EnergyPolicy, 32(4). https://doi.org/10.1016/s0301-4215(03)00156-3

Burtraw, D., Krupnick, A., Palmer, K., Palmer, K., Paul, A., Toman, M., \& Bloyd, C. (2003). Ancillary Benefits of Reduced Air Pollution in the US from Moderate Greenhouse Gas Mitigation Policies in the Electricity Sector. Environmental Economics and Management, 45(3). https://doi.org/10.1016/S0095-0696(02)00022-0

Dai, X. H. (2012). Green Poverty Alleviation: the inevitable choice of fiscal support policy in the central and western regions of China-from the perspective of financial policy support in Sichuan. Rural Economy, (12).

Guo, H. C., Zhang, Z. X., \& Chen, B. (2004). Anti-Poverty and Environment Sustainability in West China:A Study for the Hemoluo District. Acta Scicentiarum Naturalum Universitis Pekinesis, (01).

Guo, Z. Y., \& Zhu, W. (2009). A Framework Analysis of Reasons of Poverty of Ethnic Minorities in Mountain Areas in China[J].Journal of South-Central University for Nationalities(Humanities and Social Sciences). (05).

Hou, Y. L.,Wen, Y. L., \& Jin, M. (2014). Research on the Impact of Forestry Ecological Construction on Mountain's Poverty Reduction. Journal of Hunan University(Social Sciences), (04).

Liu, G., Shen, L., \& Liu, X. J. (2007). Harmonious Interactions between Economic Development and Ecological Environment Conservation in Resource-Rich and Economy-Poor Regions: A Case in Yulin City, Shaanxi Province. Resources Science, (04)

Liu, H., \& Yerken, W. (2013). A Strategy on Eco-poverty Alleviation in Western China.China Population, Resources and Environment, (10).

Lu, Y. L., Ding, S. B., Wang, R. C., \& Wang, Y. (2010). Sustainable Development of Vulnerable Ecological Regions Underthe Perspective of Regional Externalities. China Population, Resources and Environment, (20).

Pan, W. Q. (2012). Regional Linkage and the Spatial Spillover Effect on Regional Economic Growth in China. Economic Research Journal, (01).

Research group of China Poverty Alleviation Research Center, Beijing Normal University, Consideration and suggestion on China Green poverty reduction index.Review of Economic Research, 2015(10).

Sun, X. M., \& Shi, M. X. (2011). Explore Agriculture Herdsman How to Get Out of Poverty from the Angle of Ecological Poverty Alleviation-San'jiangyuan as an Example. Advances in Artificial Intelligence (Volume3)-Proceedings of 2011 International Conference on Management Science and Engineering (MSE2011).

Zha, Y., Wang, H. R., Cai, D. X., \& Wu, X. P. (2012). Status and Strategies on Ecosystem Services for Poverty Alleviation in Ningxia. Chinese Journal of Agricultural Resources and Regional Planning, (01).

Zhang, L.J., Lv, K. Y., \& Zhu, L. Z. (2008). Implementation of ecological poverty alleviation strategy to improve the overall effect of ecological construction and poverty alleviation work. Journal of Agricultural Science and Technology, (01).

\section{Copyrights}

Copyright for this article is retained by the author(s), with first publication rights granted to the journal.

This is an open-access article distributed under the terms and conditions of the Creative Commons Attribution license which permits unrestricted use, distribution, and reproduction in any medium, provided the original work is properly cited. 